\title{
Disease Severity and Yield of Sweet Corn Hybrids with Resistance to Northern Leaf Blight
}

\author{
J. K. Pataky, Department of Crop Sciences, University of Illinois, Urbana 61801; R. N. Raid, Department of Plant \\ Pathology, University of Florida, IFAS, Everglades Research Station, Belle Glade 33430-8003; L. J. du Toit, De- \\ partment of Crop Sciences, University of Illinois; and T. J. Schueneman, Department of Plant Pathology, Univer- \\ sity of Florida
}

\begin{abstract}
Pataky, J. K., Raid, R. N., du Toit, L. J., and Schueneman, T. J. 1998. Disease severity and yield of sweet corn hybrids with resistance to northern leaf blight. Plant Dis. 82:57-63.

Reactions of supersweet (sh2) sweet corn to northern leaf blight (NLB) and associated yields were evaluated in Belle Glade, Florida and Urbana, Illinois in yield-loss trials, hybrid evaluations, and evaluations of breeding materials. Hybrids differed significantly for NLB in all trials. Severity of NLB ranged from 0 to $66 \%$ on 35 sh 2 hybrids in yield-loss trials, and from 0 to $60 \%$ on 80 sh 2 hybrids in hybrid evaluations. NLB ratings ranged from 1 to 9 (approximately 0 to $80 \%$ severity) on 375 hybrids and 186 inbred lines in evaluations of breeding materials. Various methods of rating NLB and ratings from multiple dates were highly correlated, with correlation coefficients ranging from 0.76 to 0.98 . Yield, measured as weight of ears and number of marketable ears from inoculated plots as a percentage of that from control plots, decreased as disease severity increased. Linear or quadratic regression models explained 31 to $70 \%$ of the variation in percent yield as a function of disease severity at harvest. The effects of NLB on yield were limited by NLB-resistance in several hybrids, including CCO 3268, Chieftain, Crisp N Sweet 710A, Day Star, Envy, Forever, GSS 1526, Jupiter, Midship, Prime Plus, Sch 5005, and SummerSweet 7630. Although high levels of partial resistance to NLB were prevalent among 375 new experimental sh2 hybrids and 186 sh2 inbred lines evaluated in 1995, use of the gene $\mathrm{HtN}$ may increase in the near future as breeders are incorporating this resistance into new inbreds and hybrids. Breeders and plant pathologists would be wise to continue improving partial resistance to NLB without using the gene $H t N$ in genotypes with adequate levels of partial resistance, because the widespread use of the gene $H t N$ will select for virulent races of Exserohilum turcicum which occur in Florida, or for races with new combinations of virulence.
\end{abstract}

Northern leaf blight (NLB), caused by Exserohilum turcicum (Pass.) K. J. Leonard \& E. G. Suggs), is a prevalent disease of sweet corn (Zea mays L.) in the United States. Fungicides are used routinely to prevent severe epidemics of NLB on nearly 20,000 ha of supersweet (sh2) hybrids grown each spring in southern and central Florida. Epidemics of NLB on sweet corn grown in the midwestern United States are associated with wet weather. Northern leaf blight can be extremely severe in Illinois, Wisconsin, and Minnesota in August and September on susceptible, sugary (sul) sweet corn hybrids grown for processing.

Northern leaf blight typically develops first on lower leaves and spreads to leaves in the middle and upper thirds of the canopy, as illustrated by a rating scale developed in the 1940s by Elliott and Jenkins (4). Reductions in the yield of field and

Corresponding author: J. K. Pataky

E-mail: j-pataky@uiuc.edu

Accepted for publication 7 September 1997.

Publication no. D-1997-1006-02R

(C) 1998 The American Phytopathological Society sweet corn have been associated with severe necrosis or chlorosis of leaves in the upper two-thirds of the canopy $(2,6,13$ 16,22-26). Slope coefficients from linear regressions of percentage yield on NLB severity have ranged from -0.2 to -0.8 , indicating a 2 to $8 \%$ reduction in yield for each $10 \%$ NLB severity (2,6,14-16). Hooker (9) proposed an index of photosynthesis based on the percentage of healthy leaf tissue at various reproductive growth stages, and assigned values of 10 , 5 , and 1 to the photosynthetic contributions to field corn grain yield derived from the upper, middle, and lower thirds of the leaf canopy. Hooker and Perkins (10) proposed that economic losses from NLB could be avoided in field corn if $75 \%$ or more of the upper leaf canopy remained uninfected for three-fourths of the grain-filling period. They suggested that blight on the lower leaves early in the season had a greater effect on hybrid appearance than on hybrid performance. In sweet corn, NLB had little or no effect on yield of partially resistant hybrids when NLB severity a week before harvest was less than $8 \%$ in the upper $75 \%$ of the leaf canopy (15), or less than $20 \%$ for the entire leaf area (16).

Sweet corn hybrids differ in their reactions to $\operatorname{NLB}(18,21,22)$. Reactions of many sweet corn hybrids are classified as resistant or partially resistant based on significantly less symptomatic leaf area than those classified as susceptible $(18,20,21,22)$, but few evaluations of resistance consider the distribution of NLB symptoms within the canopy. Severity of NLB usually is less than $20 \%$ when partially resistant hybrids are inoculated in disease nurseries in Illinois (21); however, NLB severity may be considerably higher on these hybrids under extremely conducive environments such as those typical of southern and central Florida.

In the past decade, the levels of partial resistance to NLB in sweet corn hybrids and the number of resistant hybrids sold commercially have increased, particularly among supersweet (sh2) hybrids developed primarily for Florida markets (18; J. K Pataky, personal observation). Symptom development is delayed until a week or two before harvest in a few sh 2 hybrids which have resistance conveyed by the dominant gene $H t N(8,19,20)$. Incubation period is normal but severity is relatively low for several sh2 hybrids with high levels of partial resistance $(19,20)$. Symptoms are less severe on partially-resistant sweet corn hybrids as the result of smaller and/or fewer lesions. NLB lesions on several "2132-type" sh2 hybrids are smaller than those on susceptible hybrids. On certain sugary enhancer hybrids (e.g., Miracle, Merlin, Argent, Tuxedo), the number of lesions is less than on susceptible hybrids, but lesions are not as small as those on some of the 2132-type sh2 hybrids. With the introduction of new sh 2 hybrids that carry $H t N$ or have high levels of partial resistance to NLB, it would be useful to approximate the level of resistance needed to prevent yield reductions due to NLB under environments conducive to severe epidemics.

The objectives of this study were to evaluate the reactions of $s h 2$ sweet corn hybrids to NLB, and to associate yield with reactions of hybrids to NLB. Preliminary analyses of reactions of new hybrids have been reported (20).

\section{MATERIALS AND METHODS}

NLB yield-loss trials. Yields of sweet corn hybrids with previously known reactions to NLB were compared in trials in which plants were inoculated with $E$. tur- 
cicum or protected from NLB with fungicides. Trials were done in 1995 and 1996 at the Everglades Research and Education Center, Belle Glade, Florida, and at the Agronomy/Plant Pathology South Farm, Urbana, Illinois. Each trial included eight replicates of 32 hybrids arranged in complete blocks. Each experimental unit at Belle Glade included four 7.6-m rows, spaced $91 \mathrm{~cm}$ apart, with approximately 35 plants per row. Each experimental unit at Urbana included four 3-m rows, spaced 76 $\mathrm{cm}$ apart, with approximately 15 plants per row. In four replicates, plants at the threeto four-leaf stage were inoculated with a spore suspension of races 0 and 1 of $E$. turcicum (12). In the remaining four replicates, fungicides were applied as needed to control NLB.

Because of limited availability of seed of some hybrids, only 30 hybrids were common to all yield-loss trials. A total of 35 sh2 hybrids from seven different seed companies were evaluated. Half of the hybrids were thought to have moderate to high levels of partial resistance to NLB. One hybrid, Day Star, displayed an $\mathrm{HtN}$ reaction to NLB. A few hybrids considered moderately susceptible to susceptible prior to these trials were included as checks.

Yield trials were planted 20 January 1995 and 7 February 1996 at Belle Glade, and 6 June 1995 and 21 May 1996 at Urbana. The trial in Urbana in 1995 was unsuccessful due to a severe drought. A spore suspension of approximately $10^{3}$ conidia per $\mathrm{ml}$ was sprayed directly into leaf whorls of plants in inoculated replicates on 24 February and 2 March 1995 and 8 and 11 March 1996 in Belle Glade, and 19, 24, and 27 June and 5 July 1996 at Urbana. Plants were near the four- to five-leaf stage of growth when inoculations commenced. A mixture of isolates of races 0 and 1 originally collected near Belle Glade (17) was used to produce inoculum as described previously (22). A mixture of mancozeb (Dithane M-45, Rohm \& Haas, Philadelphia, PA) at the rate of $1.68 \mathrm{~kg}$ per ha, and propiconazole (Tilt 3.6E, Ciba Corp., Greensboro, NC) at the rate of 0.29 liters per ha, was applied to plants in non-inoculated replicates in Belle Glade on 3, 10, and 22 March and 4 April 1995, and 15 March and 5, 12, and 23 April 1996. Fungicides were not needed in the non-inoculated replicates in Urbana.

Severity of NLB was rated on 5, 14, 19, and 22 April 1995 and 5 and 9 May 1996 in Belle Glade, and on 6 August 1996 in Urbana. A 0 to 5 scale similar to that of Elliott and Jenkins (4), a Horsfall-Barratt scale (11), and a linear scale of percentage of symptomatic leaf area from 0 to $100 \%$ were used at Belle Glade in 1995. In 1996, the 0 to 5 scale and percentage ratings were used at Belle Glade. At Urbana, severity of symptomatic leaf area was rated from 0 to $100 \%$ and from 0 to 9 , where 1 to 9 ratings were approximately the square root of the percentage of symptomatic leaf area. All ratings were done on a whole-plot basis, where the rating represented a visual evaluation of all plants in a plot. On some rating dates, each plot was given two ratings (e.g. $25 \%$ and $30 \%$ ) to account for variation among plants in a plot or between two raters. Common rust (Puccinia sorghi Schwein.) occurred naturally prior to tasseling at Belle Glade in 1996. Severity of rust was rated in the same manner as severity of NLB. The total leaf area affected by both diseases also was rated separately from the individual ratings for each disease.

Primary ears from consecutive plants in the middle two rows of each experimental unit were harvested about 21 days past the mid-silk growth stage. Twenty-five ears were harvested per plot in Belle Glade in 1995, and 20 ears were harvested from plots at both locations in 1996. Ears were weighed after husking, and marketable and non-marketable ears were counted. Harvest dates, which varied among hybrids due to maturity differences, were from 21 to 27 April 1995 and 1 to 9 May 1996 at Belle Glade, and 4 to 14 August 1996 at Urbana.

Disease ratings, ear weights, and number of marketable ears were analyzed separately by analysis of variance (ANOVA) for the inoculated and non-inoculated replicates of each trial. Hybrid means were compared by Bayesian LSD (BLSD) mean separation tests $(k=100)$. Correlations among various rating methods and dates were calculated. Hybrid means for ear weight and number of marketable ears were used to calculate the yield of inoculated treatments as a percentage of noninoculated treatments. Associations between percentage yield and severity were analyzed by ordinary least squares regressions. All analyses were done with SAS software (SAS Institute, Cary, NC).

Hybrid evaluations. Eighty supersweet (sh2) hybrids, including 40 yellow, 26 bicolor, and 14 white hybrids, from nine different seed companies were evaluated at Belle Glade and Urbana in 1996. Of the 35 hybrids in the yield-loss trials, 33 were included for comparisons. The remaining 47 hybrids were primarily new releases or experimental lines for which public evaluation of reactions to NLB was limited.

In Belle Glade, each experimental unit consisted of a single row, $7.6 \mathrm{~m}$ long, containing about 35 plants; in Urbana, the single row was $3 \mathrm{~m}$ long and contained about 15 plants. The experimental design was a randomized complete block with four replicates. Trials were planted on 7 February 1996 at Belle Glade and on 20 May 1996 at Urbana. Plants were inoculated with $E$. turcicum as described for the yield-loss trials. Severity of NLB was rated from 0 to $100 \%$ on 8 May 1996 at Belle Glade and 14 August 1996 at Urbana. NLB also was rated from 0 to 5 at Belle Glade and from 0 to 9 at Urbana. Severity of naturally occurring common rust was rated from 0 to $100 \%$ on the modified Cobb scale and from 0 to 5 at Belle Glade. The total leaf area affected by both diseases at Belle Glade also was rated separately from the individual ratings for each disease.

Primary ears were harvested from 15 consecutive plants per row about 21 days past the mid-silk growth stage at Belle Glade. Ears were weighed after husking, and marketable and non-marketable ears were counted. Harvest dates varied among hybrids due to maturity differences and ranged from 29 April to 9 May 1996.

Disease ratings, ear weights, and number of marketable ears were analyzed by ANOVA. Hybrid means were compared by BLSD mean separation tests $(k=100)$. Correlations among various rating methods and trials were calculated. Hybrid means were used to group hybrids into categories of those with (i) severity greater or less than $30 \%$, (ii) those with more or less than $90 \%$ of the ears marketable, and (iii) those with ears weighing more or less than 270 grams. Associations among disease severity and yield (ear weight and number of marketable ears) were examined using Chisquare tests of independence.

Evaluations of breeding materials. Inbred breeding lines and unreleased experimental hybrids were rated for reactions to NLB in the Belle Glade area in 1995 in order to examine the reactions of materials that might potentially be grown in Florida in the next few years. A total of 186 sh2 inbred lines (at various stages of inbreeding) and 375 experimental sh2 hybrids from three commercial seed companies and the Florida Agriculture Experiment Station were evaluated in non-replicated plots located in the middle of three fields where sweet corn was being produced commercially. Plants in two of the three trials were not sprayed with fungicides, and the third received fewer applications than the adjacent, commercial field. Plants at the 3- to 4-leaf stage in one of the fields were inoculated with a mixture of races 0 and 1 of E. turcicum, as described above. Approximately 15 standard hybrids (Challenger, Day Star, Florida Staysweet, Frontier 3030, Summer Sweet 7630, Summer Sweet 8102, Summer Sweet 7631, Ultimate, and others) were common to each trial, allowing results to be compared between locations. Each experimental unit consisted of one or two rows, 3 or $7.6 \mathrm{~m}$ long, containing 15 or 35 plants per row, respectively.

Severity of NLB was rated on a wholeplot basis on a 0 to 9 scale, where ratings were approximately the square root of the percentage of symptomatic leaf area. Distributions of the ratings of inbreds and hybrids were examined.

\section{RESULTS}

NLB-yield-loss trials. A month before harvest, severity of NLB ranged from 0 to 
$30 \%$ among inoculated plots in Belle Glade in 1995, and from 0 to $25 \%$ at both locations in 1996. Severity of NLB in inoculated plots at harvest ranged from 2 to $66 \%$ in Belle Glade in 1995, from 0 to $38 \%$ in Urbana in 1996, and from 1 to $48 \%$ in Belle Glade in 1996 (Table 1). In fungicide-protected control plots, severity of NLB at harvest ranged from 0 to $11 \%$ in Belle Glade in 1995, and was less than 5\% for all hybrids in Urbana and Belle Glade in 1996. Severity of naturally occurring common rust ranged from 0 to $50 \%$ at harvest in plots inoculated with $E$. turcicum in Belle Glade in 1996, but was less than $5 \%$ in plots protected with fungicides.

Various methods of rating NLB and ratings from multiple dates were highly correlated. Correlation coefficients for NLB ratings calculated at harvest using various rating methods ranged from 0.94 to 0.98 . Correlation coefficients for NLB ratings taken earlier in the season using various rating methods ranged from 0.84 to 0.96 . Correlation coefficients for NLB ratings at different times ranged from 0.84 to 0.96 for consecutive ratings, and from 0.76 to 0.86 for all other combinations of ratings.

Hybrids differed significantly for severity of NLB at harvest in all three trials, and for rust severity in Belle Glade in 1996 (Table 1). Severity of NLB was less than $2 \%$ on Day Star, on which most lesions had not yet passed through the incubation period due to the $H t N$-reaction. Separation of hybrids was more distinct in Belle Glade in 1995, when NLB was more severe than in other trials. For example, severity of NLB was significantly lower on Prime Plus (15\%) than on other hybrids (except Day Star) in Belle Glade in 1995, whereas in the other two trials, Prime Plus was grouped with several hybrids for which severity of NLB was relatively low (less than 15\%). Severity of NLB was less than $30 \%$ for 13 hybrids in Belle Glade in 1995, and less than $15 \%$ for 13 hybrids at both locations in 1996. Nine hybrids had relatively low NLB severity in all trials (less than $30 \%$ in 1995 or less than $15 \%$ in 1996), including Chieftain, Day Star, Jupiter, Midship, Prime Plus, Sch 5005,
SummerSweet 7630, SummerSweet 7631, and XPH 3056 (Table 1).

Yield (measured as weight of ears and number of marketable ears from inoculated plots as a percentage of that from control plots) decreased as disease severity increased (Fig. 1). The independent variable, disease severity (\%), differed slightly among the regression analyses of data from the three trials. In Belle Glade in 1995, the difference in NLB severity from inoculated and control plots was used as the independent variable because severity was as great as $12 \%$ in some control plots. In 1996, this difference was not calculated because severity was less than $5 \%$ in all control plots. Natural infection with common rust was more severe in Belle Glade in 1996 than in the other two trials, so severity of the total leaf area affected by NLB and common rust was used as the independent variable (i.e., disease severity). Multiple regression models using severity of NLB and rust as separate independent variables did not account for more of the variation in either dependent vari-

Table 1. Severity of northern leaf blight (NLB) and common rust at harvest of supersweet (sh2) sweet corn hybrids in yield loss trials in Belle Glade, Florida and Urbana, Illinois in 1995 and 1996

\begin{tabular}{|c|c|c|c|c|c|}
\hline \multirow[b]{2}{*}{ Kernel color and hybrid } & \multirow[b]{2}{*}{ Seed company } & \multirow{2}{*}{$\frac{\text { Belle Glade } 1995}{\text { NLB }}$} & \multirow{2}{*}{$\frac{\text { Urbana } 1996}{\text { NLB }}$} & \multicolumn{2}{|c|}{ Belle Glade 1996} \\
\hline & & & & NLB & Rust \\
\hline \multicolumn{6}{|l|}{ Bi-color } \\
\hline Cabaret & Seminis & $41^{\mathrm{a}}$ & $24^{\mathrm{a}}$ & $24^{\mathrm{a}}$ & $17^{\mathrm{b}}$ \\
\hline Festival & Seminis & 59 & 22 & 36 & 16 \\
\hline HMX 3362 BS & Harris Moran & 45 & 26 & 23 & 0 \\
\hline Headliner & IFSI & $\ldots$ & $\ldots$ & 10 & 30 \\
\hline Quest & Rogers Sandoz & 45 & 15 & 28 & 23 \\
\hline Starship & Seedway/MM & 33 & 17 & 17 & 21 \\
\hline SummerSweet 7702 & Abbott \& Cobb & 25 & $\ldots$ & $\ldots$ & $\ldots$ \\
\hline SummerSweet 8102 & Abbott \& Cobb & 37 & 21 & 17 & 23 \\
\hline \multicolumn{6}{|l|}{ White } \\
\hline Even Sweeter & Seminis & 35 & 25 & 29 & 25 \\
\hline Frontier 3030 & Seminis & 58 & 27 & 27 & 28 \\
\hline Pegasus & Crookham & 41 & 21 & 32 & 20 \\
\hline Snowbird & Rogers Sandoz & 66 & 38 & 48 & 19 \\
\hline SummerSweet 7631 & Abbott \& Cobb & 26 & 6 & 13 & 30 \\
\hline \multicolumn{6}{|l|}{ Yellow } \\
\hline Chieftain & IFSI & 26 & 10 & 9 & 0 \\
\hline Day Star & Harris Moran & 2 & 0 & 1 & 24 \\
\hline Endeavor & Seminis & 37 & 21 & 20 & 16 \\
\hline Envy & Seedway/MM & $\ldots$ & 10 & 13 & 0 \\
\hline Florida Staysweet & IFSI & 41 & 17 & 17 & 50 \\
\hline Flagship & Seedway/MM & 41 & 14 & 18 & 22 \\
\hline Forever & Seminis & 22 & 16 & 10 & 43 \\
\hline Fortune & IFSI & $\ldots$ & 22 & $\ldots$ & $\ldots$ \\
\hline GSS 4606 & Rogers Sandoz & 24 & 12 & 21 & 24 \\
\hline Jupiter & Seedway/MM & 23 & 8 & 10 & 21 \\
\hline Midship & Seedway/MM & 27 & 9 & 14 & 21 \\
\hline Prime Plus & Rogers Sandoz & 15 & 10 & 9 & 0 \\
\hline Primetime & Rogers Sandoz & 20 & 9 & 17 & 21 \\
\hline Punchline & Seminis & 35 & 16 & 19 & 23 \\
\hline Sch 5005 & IFSI & 27 & 10 & 8 & 16 \\
\hline Sch 51092 & IFSI & 34 & $\ldots$ & $\ldots$ & $\ldots$ \\
\hline Sch 5276 & IFSI & 34 & 16 & 12 & 21 \\
\hline Sch 81615 & IFSI & 38 & 13 & 27 & 22 \\
\hline SummerSweet 7630 & Abbott \& Cobb & 28 & 7 & 10 & 28 \\
\hline SummerSweet 7710 & Abbott \& Cobb & 32 & 15 & 17 & 31 \\
\hline Ultimate & Harris Moran & 36 & 19 & 19 & 24 \\
\hline XPH 3056 & Seminis & 27 & 11 & 10 & 33 \\
\hline Bayesian LSD $(k=100)$ & & 3.8 & 4.2 & 4.1 & 3.3 \\
\hline
\end{tabular}

a Severity of NLB rated as percentage of leaf area infected on a whole-plot basis.

${ }^{\mathrm{b}}$ Severity of rust rated as percentage of leaf area infected on a whole-plot unit basis. 
able than did a single independent variable, total disease severity. Severity of NLB in inoculated plots was the independent variable for the analysis of data from Urbana.

Yield (measured as weight of ears from inoculated plots as a percentage of that from control plots) decreased as disease severity increased (Fig. 1A, B). Linear or quadratic regression models explained 34 to $62 \%$ of the variation in percentage ear weight as a function of disease severity at harvest (Fig. 1A). In each trial, ear weight was greater than $90 \%$ of the control when disease severity was less than $25 \%$. The slope coefficient from the regression model based on all trials was -0.33 , indicating that ear weight was greater than $90 \%$ of the controls when disease severity was less than 30\% (Fig 1B).

Yield (measured as number of marketable ears from inoculated plots as a percentage of those from control plots) decreased as disease severity increased (Fig. 1C, D). Linear or quadratic regression models explained 31 to $70 \%$ of the variation in percentage marketable ears as a function of disease severity at harvest (Fig. 1C). In the two trials in Belle Glade, the number of marketable ears was greater than $90 \%$ of the control when disease se- verity was less than $30 \%$. In Urbana, the number of marketable ears was greater than $90 \%$ of the control when disease severity was less than $20 \%$. Based on a single regression model from all trials, the number of marketable ears was greater than $90 \%$ of the controls when disease severity was less than $30 \%$ (Fig 1D); however, compared to individual regression models, the combined model underestimated the detrimental effects of disease on marketable ears when severity was greater than $20 \%$ in Urbana in 1996, and overestimated the detrimental effects of disease on marketable ears when severity was greater than $40 \%$ in Belle Glade in 1996 (Fig 1D). Thus, interpretation of the combined analysis is not appropriate due to the significant interaction among trials.

Hybrid evaluations. Severity of NLB ranged from 0 to $60 \%$ in Belle Glade and from 0 to $53 \%$ in Urbana. Severity of naturally occurring common rust ranged from 0 to $54 \%$ in Belle Glade. Correlation coefficients for NLB and rust ratings using different rating methods were 0.95 or higher. Correlation coefficients for NLB ratings from the two trials ranged from 0.84 to 0.86 .

Hybrids differed significantly for severity of NLB in both trials and for severity of rust in Belle Glade. BLSD values were 9.3, 6.2 , and $4.4 \%$ for severity of NLB in Belle Glade and Urbana and for severity of rust in Belle Glade, respectively. Reactions of individual hybrids in these trials were reported previously (20) and are available from the first or second author upon request. Severity of NLB was less than $15 \%$ in Belle Glade and less than $10 \%$ in Urbana for the 9 hybrids that had relatively low NLB severity in the yield-loss trials as noted above. Severity of NLB in Belle Glade and Urbana also was less than 15 and $10 \%$, respectively, for 5 hybrids grouped among those with the least severe NLB in at least one of the three yield-loss trials, including Envy, Forever, Sch 5276, SummerSweet 7702, and SummerSweet 7710. Severity of NLB was less than $15 \%$ in both trials for 10 hybrids not included in the yield-loss trials, including CCO 3268 , Crisp N Sweet 710A, Crisp N Sweet 711, GSS 1526, HMX 4343 S (HtN-reaction), HMX $5351 \mathrm{~S}$ (HtN-reaction), Peter 445, WSS 9748, XPH 3076, and XSC 1036 BC.

Yield (weight of ears and percentage of marketable ears) and disease severity (NLB and rust) were not highly correlated in the hybrid trial in Belle Glade, but these variables were not independent (Fig. 2).

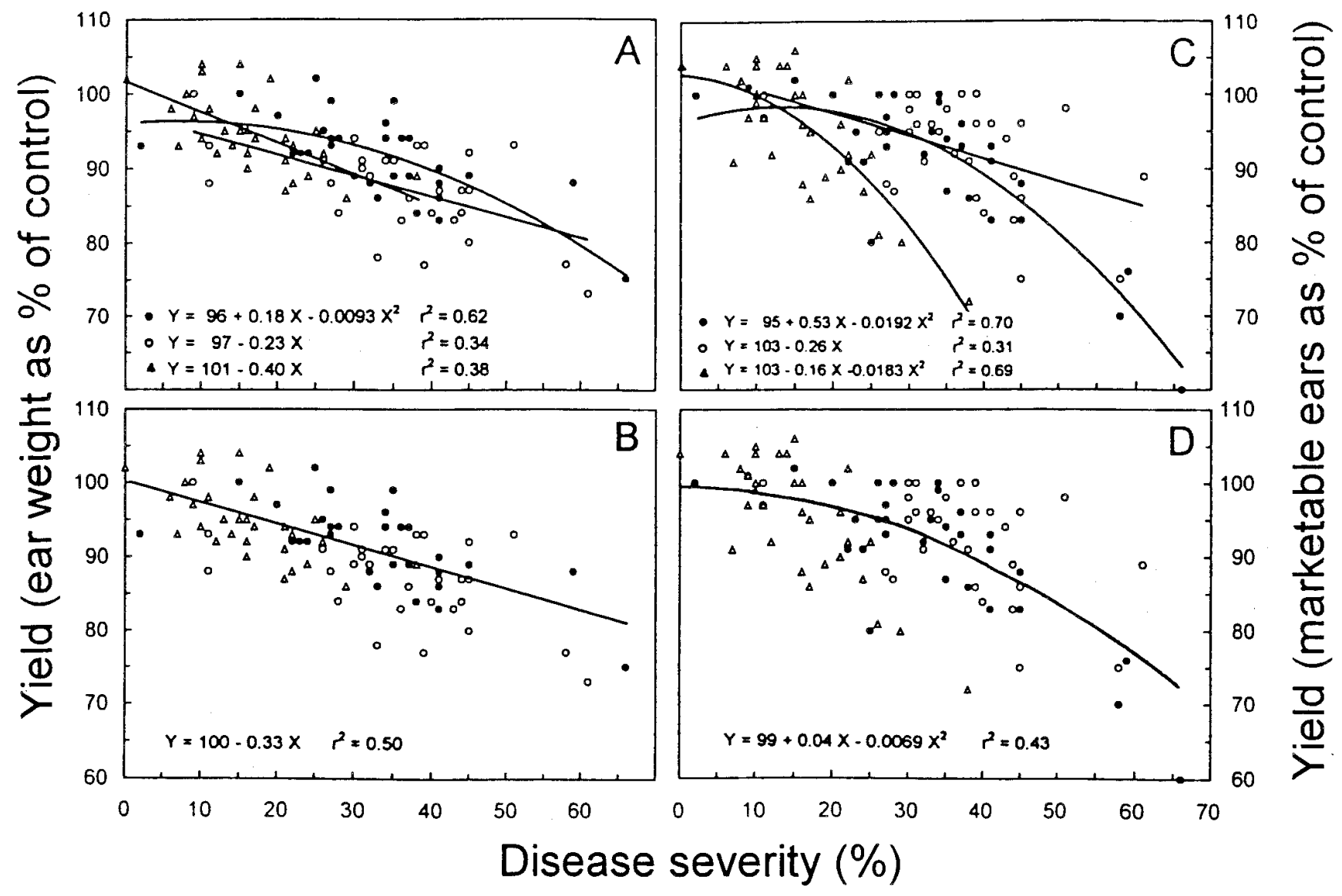

Fig. 1. Effect of northern leaf blight (NLB) on relative yield of 35 supersweet (sh2) sweet corn hybrids measured in three trials, 1995 in Belle Glade, Florida (•), 1996 in Belle Glade (o), and 1996 in Urbana, Illinois ( $\Delta$ ): (A) yield measured as weight of ears analyzed individually from three trials; (B) combined analysis of yield measured as weight of ears; (C) yield measured as marketable ears analyzed individually from three trials; and (D) combined analysis of yield measured as marketable ears. Disease severity measured as percentage of the total infected leaf area due to NLB in 1995 and in Urbana in 1996, and due to NLB and naturally occurring common rust in Belle Glade in 1996. 
Ears weighed more than 270 grams for $91 \%$ of the hybrids for which disease severity was less than $30 \%$, but ear weight was greater than 270 grams for only $48 \%$ of the hybrids for which disease severity was greater than $30 \%$ (Fig 2A). The Chisquare value for the test of independence was $7.08(P=0.008)$. Similarly, more than $90 \%$ of all ears were marketable for $82 \%$ of the hybrids that had disease severity of less than $30 \%$, but more than $90 \%$ of all ears were marketable for only $46 \%$ of the hybrids with disease severity greater than $30 \%$ (Fig. 2B). The Chi-square value for the test of independence was $5.152(P=$ 0.026). Thus, the percentage of hybrids with small ears or non-marketable ears was significantly higher for hybrids with disease severity greater than $30 \%$ than for hybrids with severity less than $30 \%$. Ten hybrids with disease severity greater than $30 \%$ had ears that weighed more than 270 grams and had more than $90 \%$ of the ears marketable. These included four hybrids (Crisp N Sweet 710A, Sch 5005, SummerSweet 7630, and SummerSweet 7702) that had partial resistance to NLB but were susceptible to rust.

Evaluations of breeding materials. NLB ratings for a total of 375 hybrids in three trials ranged from 1 to 7 on a scale of 0 to 9 (Fig. 3A). Reactions and ranks of standard hybrids were as expected, as hybrids with partial resistance to NLB were rated 3 or 4 , and relatively susceptible hybrids were rated 6 and 7. Twelve hybrids

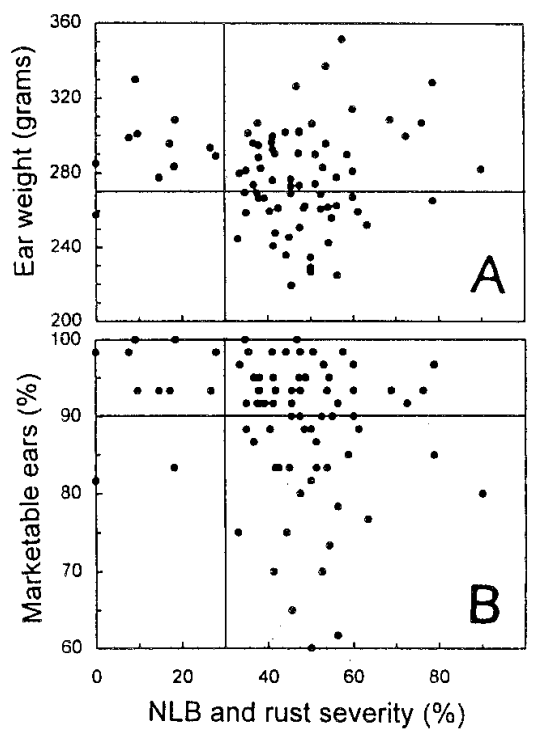

Fig. 2. Yield of 80 supersweet $(s h 2)$ sweet corn hybrids inoculated with Exserohilum turcicum or naturally infected by Puccinia sorghi and disease severity at harvest in Belle Glade, Florida in 1996. Yield measured as (A) weight of ears or (B) number of marketable ears was not independent of disease severity based on Chi-square tests of independence for groups of hybrids with severity greater and less than $30 \%$, hybrids with ears weighing more or less than 270 grams, and hybrids with greater or less than $90 \%$ marketable ears. with $H t N$-reactions or exceptionally high levels of partial resistance to NLB were rated 1 or 2 . One hundred eighty hybrids were rated 3 or 4 , including some hybrids for which NLB severity was less than $36 \%$ in the yield-loss trial in Belle Glade in 1995. One hundred eighteen hybrids were rated 5, including some hybrids for which NLB severity ranged from 27 to $40 \%$ in the yield-loss trial in Belle Glade in 1995. Sixty-five hybrids were rated 6 or 7 , including some hybrids for which NLB severity was greater than $37 \%$ in the yieldloss trial in Belle Glade in 1995.

NLB ratings for inbred lines ranged from 1 to 9 in the three trials (Fig. 3B). Twenty lines had $\mathrm{HtN}$-reactions, although some were segregating for this phenotype. NLB severity was relatively low on 48 lines rated 2,3 , or 4 , and moderate on 18 lines rated 5. NLB was severe on 81 lines rated 6 or 7 , and extremely severe on 19 lines rated 8 or 9 .

\section{DISCUSSION}

Several sh2 sweet corn hybrids have levels of partial resistance to NLB that should prevent or limit the detrimental effects of NLB on yield under most situations. Although relationships between sweet corn yield and disease severity varied slightly in this study, NLB and common rust had little effect on ear weight or number of marketable ears when disease severity was relatively low. Yield reductions were less than $10 \%$ when disease severity was less than 20 or $30 \%$, depending upon the trial and method of measuring yield. These results, which are based on evaluations of a greater number of sweet corn hybrids than earlier yield-loss trials,

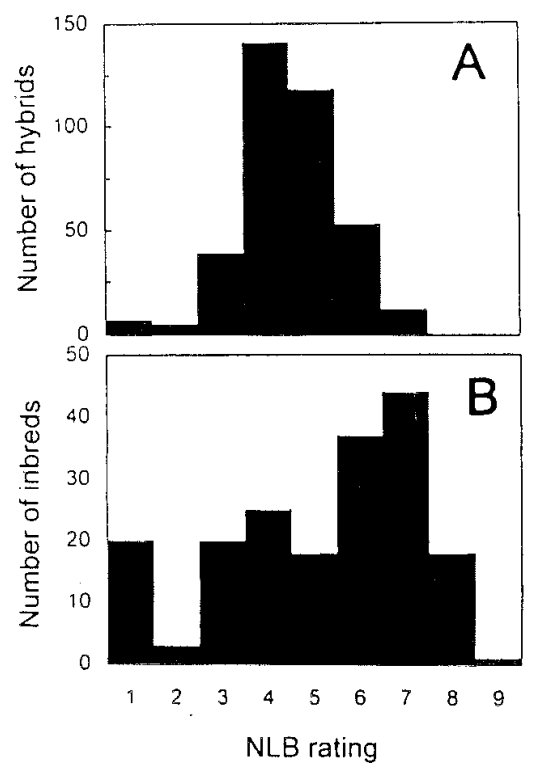

Fig. 3. Reactions to northern leaf blight rated on a 1 to 9 scale for (A) 375 supersweet $(\operatorname{sh} 2)$ sweet corn hybrids and (B) 186 inbred breeding lines evaluated in three trials adjacent to commercial fields in Belle Glade, Florida in 1995. corroborate previous findings $(15,16,25)$ which support the proposition of Hooker and Perkins (10) that blight on the lower leaves of maize plants has a greater effect on hybrid appearance than on hybrid performance.

In this study, we did not attempt to measure the actual, non-symptomatic leaf area or to partition the amount of NLB or common rust by leaf position or portions of the canopy. Leaf area and NLB severity were measured for each leaf in a previous study (15), from which it was concluded that severe NLB in the lower $25 \%$ of the canopy did not affect sweet corn yield. The 20 or $30 \%$ "yield-loss threshold" that was observed on the partially resistant hybrids in this study probably resulted from most of the symptoms occurring in the bottom third of the canopy. Although regression models from this study were slightly different from those of previous studies, results from several studies indicate that sweet corn yield is not affected greatly by low amounts of disease at harvest $(3,8,15,16,22,25)$. Slope coefficients of linear relationships between yield and disease severity varied from -0.23 to 0.40 in some trials of this study, while in other trials of this study this relationship was explained best by quadratic functions for which the incremental effects of disease on yield were less at lower severities. In previous examinations of the relationships between sweet corn yield and NLB or common rust, slope coefficients for linear relationships ranged from -0.3 to $-0.8(15,16,22)$. In one study $(16)$, negligible effects of low amounts of disease on lower leaves was taken into account by measuring disease severity in the upper $75 \%$ of the canopy. In other studies in which regressions were based on disease rated with ordinal scales, e.g., 1 to 9 (8), or where qualitative treatments were compared $(3,25)$, low amounts of disease had minimal effects on sweet corn yield.

Correlations between yield (ear weight and marketable ears) and disease severity were low in 1996 in the hybrid evaluation because yields were relatively high for several hybrids with severity greater than $30 \%$ (Fig. 2). Possibly, these hybrids are tolerant, particularly with respect to yield measured as number of marketable ears. Common rust, NLB, and other stresses often cause ears to be non-marketable because of poor tip fill. Genotypes that fill kernels at the tip of the ear in spite of stresses would tend to be marketable even if ear size (length, width, diameter, weight) was decreased. Hence, disease on these hybrids may affect yield measured as weight or size, but it may not affect yield based on number of marketable ears. Similarly, the lack of correlation between ear weight and severity in the hybrid evaluation in 1996 may have resulted from hybrids with severity greater than $30 \%$ 
having particularly large ears in the absence of NLB or rust.

Severity of NLB was below levels that could reduce yields substantially for at least 9 of $35 \operatorname{sh} 2$ hybrids in the yield-loss trials, and for an additional 15 hybrids evaluated in 1996. Of these 24 hybrids, 3 displayed $H t N$-reactions to E. turcicum, and the other 21 hybrids had high levels of partial resistance to NLB. The inbred parents of commercial sweet corn hybrids with partial resistance to NLB are not known publicly, but the plant characteristics of many of these hybrids were typical of those with at least one inbred parent derived from $\mathrm{Fa} 32$, the sh2 conversion of the sugary inbred Ia 2132. To develop the inbred $\mathrm{Fa} 32$ and the hybrid Florida Staysweet for the NLB-conducive environments of central and southern Florida, Wolf $(27,28)$ incorporated the NLB-resistance gene $\mathrm{Htl}$ and selected for partial resistance. Apparently, commercial sweet corn breeders developing new $s h 2$ hybrids for Florida markets have improved the levels of partial resistance to NLB in 2132lines and other germ plasm. Florida Staysweet was not one of the hybrids having relatively low NLB severity, even though it was included in all three sets of our trials (yield loss, hybrid evaluations, and evaluations of breeding materials). Similarly, the gene $H t l$ was relatively ineffective in our trials due to the prevalence of race 1 of E. turcicum in Florida (17) and the use of isolates of race 1 as inoculum.

Although high levels of partial resistance to NLB were prevalent among 375 new experimental sh2 hybrids and 186 sh 2 inbred lines evaluated in 1995, use of the gene $H t N$ may increase in the near future as this resistance is incorporated into new inbreds and hybrids. Among the 20 inbred lines that segregated for $H t N$ reactions, some had extremely susceptible htn-phenotypes, while others had htn-phenotypes with relatively high levels of partial resistance. Incorporation of $\mathrm{HtN}$ resistance into susceptible backgrounds, such as C13- or Jubilee-derived materials, would improve these materials for environments that are conducive to NLB; however, incorporation of $\mathrm{HtN}$ resistance into materials that already have high levels of partial resistance may not be prudent. Continued improvement of partial resistance to NLB without using the gene HtN in highly resistant materials would be wise, because the widespread use of the gene $H t N$ will select for virulent races that already occur in Florida (17), and for races with new combinations of virulence (5).

Although the use of the gene $H t N$ in materials with relatively high levels of partial resistance may be an unwise genedeployment strategy, this may occur because of consumer (grower) preferences. Growers may prefer hybrids with $\mathrm{HtN}$ resistance to NLB and $R p$ resistance to common rust in environments similar to that of Belle Glade because none of the leaf tissue will be severely affected by these two diseases, whereas $R p$-resistant hybrids with high levels of partial resistance to NLB might have 15 to $30 \%$ NLBinfected leaf area. Since initial NLB infection is concentrated in the lower third or half of the leaf canopy, the appearance of $\mathrm{Ht} \mathrm{N}$-resistant hybrids would be much better than that of hybrids with partial NLB resistance, even though, based on our results, the performance of these two groups of hybrids will be quite similar with respect to yield responses to NLB. Nevertheless, $H t N$-resistant hybrids might reduce disease-control costs for risk-averse growers who begin fungicide spray programs at the initial appearance of symptoms. Also, $H t N$ resistance could prevent NLB lesions on husk leaves, which can be a cosmetic problem of fresh-market sweet corn.

As new sh 2 hybrids are developed and introduced, these materials should be evaluated to determine if levels of NLB resistance are adequate to minimize the effects of NLB. Various ratings scales based on ordinal or ratio measurements of disease (or some combination of these two methods) were highly correlated in our study. Thus, the exact rating scale used to assess disease reactions of new hybrids may not be as important as the set of NLBresistant hybrids against which the new hybrids are compared. This set of standards may include hybrids such as CCO 3268, Chieftain, Crisp N Sweet 710A, Day Star, Envy, Forever, GSS 1526, Jupiter, Midship, Prime Plus, Sch 5005, SummerSweet 7630, and Ultimate. The resistance of these hybrids limits the effects of NLB on yield. Under environmental conditions conducive to severe NLB, the resistance of some of these hybrids may prove to be better than that of others, whereas under less severe conditions, the reactions of these hybrids may be impossible to separate. Adipala et al (1) observed a similar response among NLB-resistant Ugandan maize cultivars. Reactions to NLB were clearly different in field trials in Uganda when NLB was severe, but the reactions of the most resistant cultivars could not be differentiated in Wooster, Ohio when conditions were less conducive for the development of NLB. Hence, further improvement of partial resistance to NLB in sweet corn will require evaluation of breeding materials in environments that are at least as conducive to NLB as those in Belle Glade.

\section{LITERATURE CITED}

1. Adipala, E., Lipps, P. E., and Madden, L. V. 1993. Reactions of maize cultivars from Uganda to Exserohilum turcicum. Phytopathology 83:217-223.

2. Bowen, K. L., and Pedersen, W. L. 1988. Effects of northern leaf blight and detasseling on yields and yield components of corn inbreds. Plant Dis. 72:952-956.
3. Dillard, H. R., and Seem, R. C. 1990. Use of an action threshold for common maize rust to reduce crop loss in sweet corn. Phytopathology 80:846-849.

4. Elliott, C., and Jenkins, M. T. 1946. Helminthosporium turcicum leaf blight of corn Phytopathology 36:660-666.

5. Fallah Moghaddam, P., and Pataky, J. K. 1994. Reactions of isolates from matings of races 1 and $23 \mathrm{~N}$ of Exserohilum turcicum. Plant Dis. 78:767-771.

6. Fisher, D. E., Hooker, A. L., Lim, S. M., and Smith, D. R. 1976. Leaf infection and yield loss caused by four Helminthosporium leaf diseases of corn. Phytopathology 66:942-944.

7. Gevers, H. O. 1975. A new major gene for resistance to Helminthosporium turcicum leaf blight of maize. Plant Dis. Rep. 59:296-299.

8. Groth, J. V., Zeyen, R. L., Davis, D. W., and Christ, B. J. 1983. Yield and quality losses caused by common rust (Puccinia sorghi Schw.) in sweet corn (Zea mays) hybrids. Crop Prot. 2:105-111.

9. Hooker, A. L., 1979. Estimating disease losses based on the amount of healthy leaf tissue during the plant reproductive period. Genetika 11:181-192.

10. Hooker, A. L., and Perkins, J. M. 1980. Helminthosporium leaf blight of corn - the state of the art. Pages 68-87 in: Proc. Annu. Corn Sorghum Res. Conf. 35th. Am. Seed Trade Assoc., Chicago, IL.

11. Horsfall, J. G., and Barratt, R. W. 1945. An improved grading system for measuring plant diseases. Phytopathology 35:655.

12. Leonard, K. J., Levy, Y., and Smith, D. R. 1989. Proposed nomenclature for pathogenic races of Exserohilum turcicum on corn. Plant Dis. 73:776-777.

13. Levy, Y., and Leonard, K. J. 1990. Yield loss in sweet corn in response to defoliation or infection by Exserohilum turcicum. J. Phytopathol. 128:161-171.

14. Pataky, J. K. 1987. Quantitative relationships between sweet corn yield and common rust, Puccinia sorghi. Phytopathology 77:10661071.

15. Pataky, J. K. 1992. Relationships between yield of sweet corn and northern leaf blight caused by Exserohilum turcicum. Phytopathology 82:370-375.

16. Pataky, J. K. 1994. Effects of races 0 and 1 of Exserohilum turcicum on sweet corn hybrids differing for Ht- and partial resistance to northern leaf blight. Plant Dis. 78:1189-1193.

17. Pataky, J. K., Carson, M. L., and Mosely, P. R 1991. Race 23N of Exserohilum turcicum in Florida. Plant Dis. 75:863

18. Pataky, J. K., du Toit, L. J., and Eastburn, D. M. 1996. Reactions of sweet corn hybrids to common rust, Stewart's wilt, and northern leaf blight: revised November 1996. Pages 162-174 in: Midwestern Vegetable Variety Trial Report for 1996. Purdue Univ. Agric. Exp. Stn. Bull. No. 737.

19. Pataky, J. K., du Toit, L. J., and Manuel, J. 1996. Sweet corn hybrid disease nursery 1996. Pages 146-161 in: Midwestern Vegetable Variety Trial Report for 1996. Purdue Univ. Agric. Exp. Stn. Bull. No. 737.

20. Pataky, J. K., du Toit, L. J., and Raid, R. N. 1996. Reactions of $s h 2$ sweet corn hybrids to northern leaf blight in trials in south Florida and central Illinois in 1996. Pages 175-178 in: Midwestern Vegetable Variety Trial Report for 1996. Purdue Univ. Agric. Exp. Stn. Bull. No. 737.

21. Pataky, J. K., and Eastburn, D. M. 1993. Using hybrid disease nurseries and yield loss studies to evaluate levels of resistance in sweet corn. Plant Dis. 77:760-765.

22. Pataky, J. K., Headrick, J. M., and 
Suparyono. 1988. Classification of sweet corn hybrid reactions to common rust, northern leaf blight, Stewart's wilt, and Goss's wilt and associated yield reductions. Phytopathology 78:172-178.

23. Perkins, J. M., and Pederson, W. L. 1987. Disease development and yield losses associated with northern leaf blight on corn. Plant Dis. 71:940-943.
24. Raymundo, A. D., and Hooker, A. L. 1981 Measuring the relationship between northern corn leaf blight and yield losses. Plant Dis. 65:325-327.

25. Solomonovish, S., Levy, Y., and Pataky, J. K. 1992. Yield losses in sweet corn cultivars in response to defoliation and to infection by Exserohilum turcicum. Phytoparasitica 20:113-121.
26. Ullstrup, A. J., and Miles, S. R. 1957. The effects of some leaf blights of corn on grain yield. Phytopathology 47:331-336.

27. Wolf, E. A. 1978. Florida Staysweet. Circ. Fla. Agric. Exp. Stn. S-259.

28. Wolf, E. A., and Showalter, R. K. 1974. Florida-Sweet: a high quality $\operatorname{sh} 2$ sweet corn hybrid for fresh market. Circ. Fla. Agric. Exp. Stn. S-226. 